\title{
Exergetic analysis of gas turbine plants
}

\section{Mohamad Javad Ebadi and Mofid Gorji-Bandpy}

Department of Mechanical Engineering, University of Mazandaran, P.O. Box 484, Babol, Iran E-mail: ebadi220@gmail.com E-mail: gorji@nit.ac.ir *Corresponding author

\begin{abstract}
An exergetic analysis was performed for a 116-MW gas-turbine power plant. Mass and energy conservation laws were applied to each component of the system. Quantitative exergy balance for each component and for the whole system was considered. In this study, the exergy of a material stream is decomposed into thermal, mechanical and chemical exergy and an entropy-production flow. The effect of a change in the inlet turbine temperature on the exergetic efficiency and exergy destruction in the plant was evaluated. The crucial dependency of the exergetic efficiency and the exergy destruction on the change in the turbine inlet temperature was confirmed.
\end{abstract}

Keywords: efficiency; exergy; gas-turbine; irreversibility.

Reference to this paper should be made as follows: Ebadi, M.J. and Gorji-Bandpy, M. (2005) 'Exergetic analysis of gas turbine plants', Int. J. Exergy, Vol. 2, No. 1, pp.31-39.

Biographical notes: Mohamad Javad Ebadi received his BS degree in mechanical engineering from the Azad University of Ahwaz, Ahwaz, Iran. At present he is an MSc Student studying mechanical engineering (energy conversion) at the University of Mazandaran, Babol, Iran.

Mofid Gorji-Bandpy received his MS in mechanical engineering from the Faculty of Engineering University of Tehran, Iran, in 1978, and in 1990 obtained his $\mathrm{PhD}$ degree in hydraulic engineering from the School of Engineering, University of Wales College of Cardiff (UWCC), UK. At present he is an Associate Professor of mechanical engineering at Mazandaran University, Iran, and a Visiting Professor in the department of Mechanical and Industrial Engineering at the University of Toronto, Canada. His major interests are advanced methods of energy conversion systems, turbomachinery, fluid mechanics, water distribution networks and the solution of both energy and environmental problems.

\section{Introduction}

In recent years, the use of exergy analysis in thermal design has been discussed and demonstrated by numerous authors (Cengel and Boles, 1998; Jones and Dugan, 1996; Moran and Shapiro, 2000; Verkhivker and Kosoy, 2001).

An exergy-based performance analysis is the performance analysis of a system based on the second law of thermodynamics that overcomes the limit of an energy-based 
analysis. Exergy is generally not conserved as energy but destroyed in the system. Exergy destruction is the measure of irreversibility that is the source of performance loss. Therefore, an exergy analysis assessing the magnitude of exergy destruction identifies the location, the magnitude and the source of thermodynamic inefficiencies in a thermal system (Flavio et al., 2000; Zhang et al., 2000).

Exergy analysis usually predicts the thermodynamic performance of an energy system and the efficiency of the system components by accurately quantifying the entropy-generation of the components.

In our study, an exergetic analysis was performed for a 116-MW gas-turbine plant, which is an existing plant located in Mahshahr, Iran. Mass and energy conservation laws were applied to each component. A quantitative exergy balance of each component was also delivered carefully. The exergy-balance equation developed by Oh et al. (1996) was used in this analysis.

\section{The gas turbine plant}

A schematic of a 116-MW gas turbine system is given in Figure 1 and shows the main work and exergy flows and the state points which we accounted for in this analysis. The system consists of an air-compressor (AC), a combustion chamber (CC), an air-preheater $(\mathrm{APH})$, and a gas-turbine (GT). The mass flow rate of air to the compressor at $26^{\circ} \mathrm{C}$ is $497 \mathrm{ks} \mathrm{s}^{-1}$ and the air-fuel ratio $\alpha$ at full load is 50 on a mass basis.

Figure 1 Gas turbine system

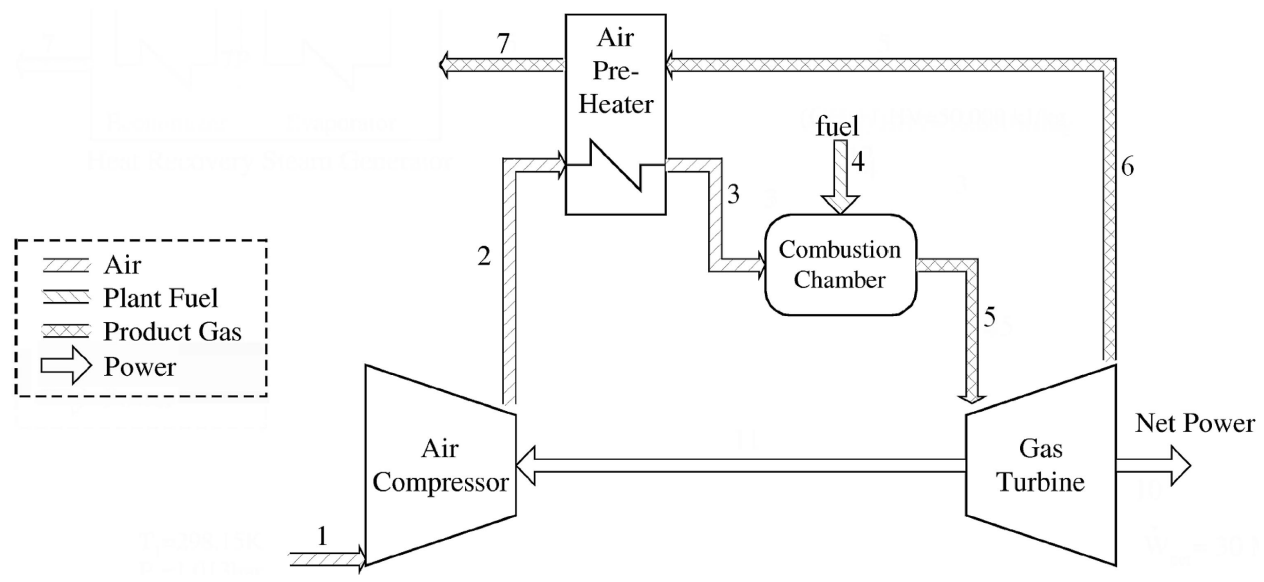

The incoming air has a temperature of $26^{\circ} \mathrm{C}$ and a pressure of $1.013 \mathrm{bar}$. The pressure increases to 8.611 bar through the compressor, which has an isentropic efficiency of $83 \%$. The inlet temperature to the turbine is $1048^{\circ} \mathrm{C}$. The turbine has an isentropic efficiency of $88 \%$. The regenerative heat exchanger has an effectiveness of $75 \%$.

The pressure drop through the air preheater is $4 \%$ of the inlet pressure for both flow streams and through the combustion chamber is $3 \%$ of the inlet pressure. The fuel (natural gas) is injected at $26^{\circ} \mathrm{C}$ and 30 bar. The pressure of the hot gas exhaust from the air preheater is 1.032 bar. 


\section{Formulation of exergy-balance equation}

A general exergy-balance equation, applicable to any component of a thermal system may be formulated by utilising the first and second laws of thermodynamics (Oh et al., 1996). The thermomechanical exergy stream may be decomposed into its thermal and mechanical components (Kwon et al., 2001). The balance gives:

$$
\dot{E}_{i}^{m}-\dot{E}_{o}^{m}=\left(\dot{E}_{i}^{T}-\dot{E}_{o}^{T}\right)+\left(\dot{E}_{i}^{P}-\dot{E}_{o}^{P}\right),
$$

where the subscripts $i$ and $o$ denote, respectively, exergy flow streams entering or leaving the plant component.

The thermal and mechanical components of the exergy stream for an ideal gas with constant specific heat may be written as (Kotas, 1995)

$$
\begin{gathered}
\dot{E}^{T}=\dot{m} c_{p}\left[\left(T-T_{r e f}\right)-T_{r e f} \ln \frac{T}{T_{r e f}}\right] \\
\dot{E}^{P}=\dot{m} R T_{r e f} \ln \frac{P}{P_{\text {ref }}}
\end{gathered}
$$

With the decomposition defined by Equation (1), the general exergy-balance equation is written as follows (Oh et al., 1996):

$$
\begin{aligned}
\dot{E}^{C H E} & +\left(\sum_{\text {inlet }} \dot{E}_{i}^{T}-\sum_{\text {outlet }} \dot{E}_{o}^{T}\right)+\left(\sum_{\text {inlet }} \dot{E}_{i}^{P}-\sum_{\text {outlet }} \dot{E}_{o}^{P}\right) \\
& +T_{\text {ref }}\left(\sum_{\text {inlet }} \dot{S}_{i}-\sum_{\text {outlet }} \dot{S}_{o}+\dot{Q}_{C V} / T_{\text {ref }}\right)=\dot{E}^{W}
\end{aligned}
$$

The term $\dot{E}^{C H E}$ in Equation (4) denotes the rate of exergy flow of fuel in the plant and $\dot{Q}_{C V}$ in the fourth term denotes the heat transfer interaction between the component and the environment.

\section{Exergy-balance equation for a gas turbine plant}

The exergy-balance equations for each component in the gas turbine plant, can be derived from the general exergy balance equation given in Equation (4). The exergy-balance equations for these components are as follows.

Air compressor

$$
\left(\dot{E}_{1}^{T}-\dot{E}_{2}^{T}\right)+\left(\dot{E}_{1}^{P}-\dot{E}_{2}^{P}\right)+T_{0}\left(\dot{S}_{1}-\dot{S}_{2}\right)=\dot{W}_{A C} .
$$

Air preheater

$$
\begin{aligned}
\left(\dot{E}_{2}^{T}-\dot{E}_{3}^{T}+\dot{E}_{6}^{T}-\dot{E}_{7}^{T}\right) & +\left(\dot{E}_{2}^{P}-\dot{E}_{3}^{P}+\dot{E}_{6}^{P}-\dot{E}_{7}^{P}\right) \\
& +T_{0}\left(\dot{S}_{2}-\dot{S}_{3}+\dot{S}_{6}-\dot{S}_{7}+\dot{Q}_{A P H} / T_{0}\right)=0
\end{aligned} .
$$


Combustion chamber

$\dot{E}^{C H E}+\left(\dot{E}_{3}^{T}+\dot{E}_{f}^{T}-\dot{E}_{5}^{T}\right)+\left(\dot{E}_{3}^{P}+\dot{E}_{f}^{P}-\dot{E}_{5}^{P}\right)+T_{0}\left(\dot{S}_{3}+\dot{S}_{f}-\dot{S}_{5}+\dot{Q}_{C C} / T_{0}\right)=0$.

Gas turbine

$$
\left(\dot{E}_{5}^{T}-\dot{E}_{6}^{T}\right)+\left(\dot{E}_{5}^{P}-\dot{E}_{6}^{P}\right)+T_{0}\left(\dot{S}_{5}-\dot{S}_{6}\right)=\dot{W}_{G T}
$$

\section{Results and discussions}

Table 1 shows chemical, thermal and mechanical exergy flow rates and entropy flow rates at various state points in the cycle. These flow rates were calculated based on the values of measured properties such as pressure, temperature, and mass flow rate at various points. Evaluations of various exergies at the inlet, and outlet of each system component are obtained by fitting appropriate polynomials (Gordon and Mcbride, 1971) to the thermophysical data in the JANAF Tables (1971).

Table 1 Property values and chemical, thermal and mechanical exergy flows and entropy production rates at various state points in the gas turbine plant at rated conditions

\begin{tabular}{lrrrrrrr}
\hline State & $\dot{m}(\mathrm{~kg} / \mathrm{s})$ & $t(K)$ & $p($ bar $)$ & $\dot{E}^{C H E}(M W)$ & $\dot{E}^{T}(M W)$ & $\dot{E}^{P}(M W)$ & $\dot{S}(M W / K)$ \\
\hline 1 & 497.00 & 299.15 & 1.013 & 0.000 & 0.000 & 0.000 & 0.000 \\
2 & 497.00 & 603.02 & 8.611 & 0.000 & 47.034 & 91.318 & 0.045 \\
3 & 497.00 & 796.91 & 8.267 & 0.000 & 102.221 & 89.580 & 0.190 \\
4 & 10.09 & 299.15 & 30.000 & 508.566 & 0.000 & 5.298 & -0.018 \\
5 & 507.09 & 1320.00 & 8.019 & 0.000 & 335.766 & 91.015 & 0.563 \\
6 & 507.09 & 861.54 & 1.075 & 0.000 & 143.181 & 2.613 & 0.607 \\
7 & 507.09 & 695.18 & 1.032 & 0.000 & 83.699 & 0.817 & 0.488 \\
\hline
\end{tabular}

The net flow rates of the various exergies crossing the boundary of each component in the gas-turbine plant at rated conditions are shown in Table 2, together with the exergy destruction in each component. Positive values indicate the exergy flow rate of products while negative values represent the exergy flow rate of resources or fuel. Here, the product of a component corresponds to the added exergy whereas the resource to the consumed exergy (Kwak et al., 2003). The sum of the exergy flow rates of products, resources and destruction equals zero for each component and for the total plant; this zero sum indicates that exergy balances are exactly satisfied.

Figure 2 shows the exergetic efficiency $\eta_{b}$ of components of the gas-turbine plant. The exergetic efficiency of the total plant is also shown: it amounts to $39 \%$. It is shown that the exergetic efficiency of the combustion chamber is much lower than that of other plant components, due to the high irreversibility in the former. 
Table 2 Net exergy flow rates and exergy destruction in the gas turbine plant at rated condition

\begin{tabular}{lrrrrr}
\hline Component & $\dot{E}^{W}(M W)$ & $\dot{E}^{C H E}(M W)$ & $\dot{E}^{T}(M W)$ & $\dot{E}^{P}(M W)$ & $\dot{E}_{D}(M W)$ \\
\hline Compressor & -151.814 & 0.000 & 47.034 & 91.318 & 13.462 \\
Air preheater & 0.000 & 0.000 & -4.295 & -3.534 & 7.829 \\
Combustion chamber & 0.000 & -508.566 & 233.545 & -3.863 & 278.884 \\
Gas turbine & 267.824 & 0.000 & -192.585 & -88.402 & 13.163 \\
Total plant & 116.010 & -508.566 & 88.699 & -4.481 & 313.338 \\
\hline
\end{tabular}

Figure 2 Exergetic efficiency of components and of total plant in the system

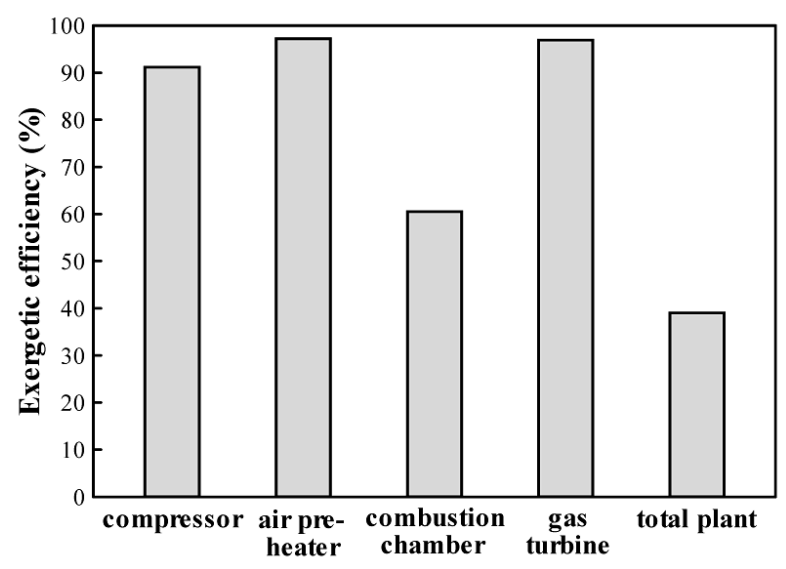

Plant components

In comparison with other plant components, the combustion chamber destructs the largest amount of total inlet exergy into the plant, as shown in Figure 3. This figure shows also that $60.97 \%$ of the total inlet exergy is annihilated in the plant.

Figure 3 Exergy destruction in components and in total plant in the system

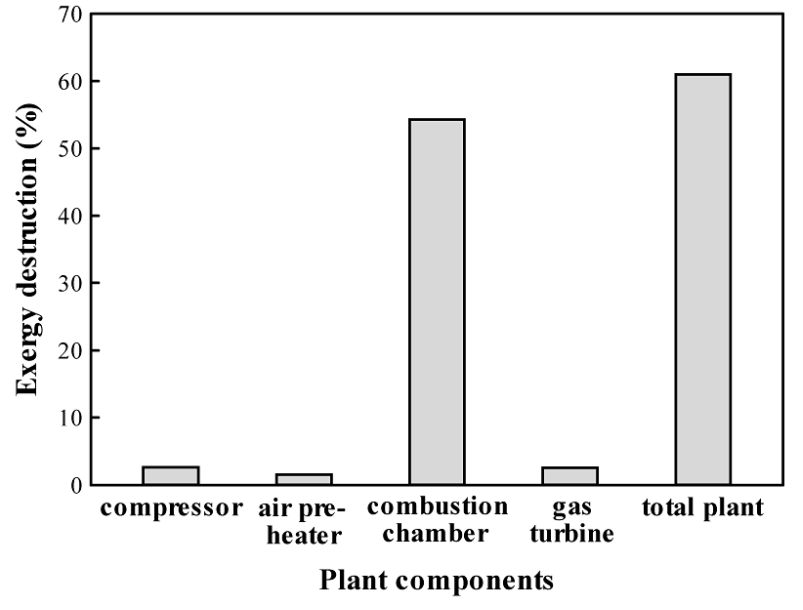


The change in the exergetic efficiency of plant components due to a variation in the turbine inlet temperature was calculated. The increase in the exergetic efficiency of components due to a $120 \%$ increase in the turbine inlet temperature is shown in Figure 4. With an increasing TIT, the exergetic efficiency of turbine increases a little, exergetic efficiency of air compressor remains constant, and exergetic efficiency of air preheater decreases a little, while there is a good increase in the exergetic efficiency of the combustion chamber, as shown in Figure 4.

Figure 4 Change in exergetic efficiency of components due to $120 \%$ increase in the turbine inlet temperature

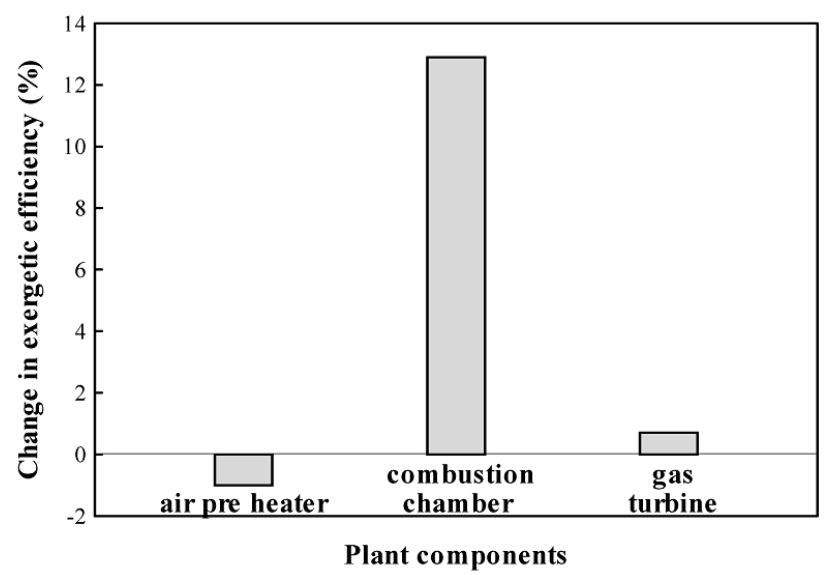

Figure 5 shows that the amount of exergy destruction $\beta$ in the combustion chamber decreases a lot for a $120 \%$ increase in the TIT, while the operation of the air compressor is not affected. There is an increase in exergy destruction in the air preheater, but because of the predominance of the irreversibility in the combustion chamber, the exergy destruction in the total plant decreases of about $23.7 \%$.

Figure 5 Change in exergy destruction in components due to $120 \%$ increase in the turbine inlet temperature

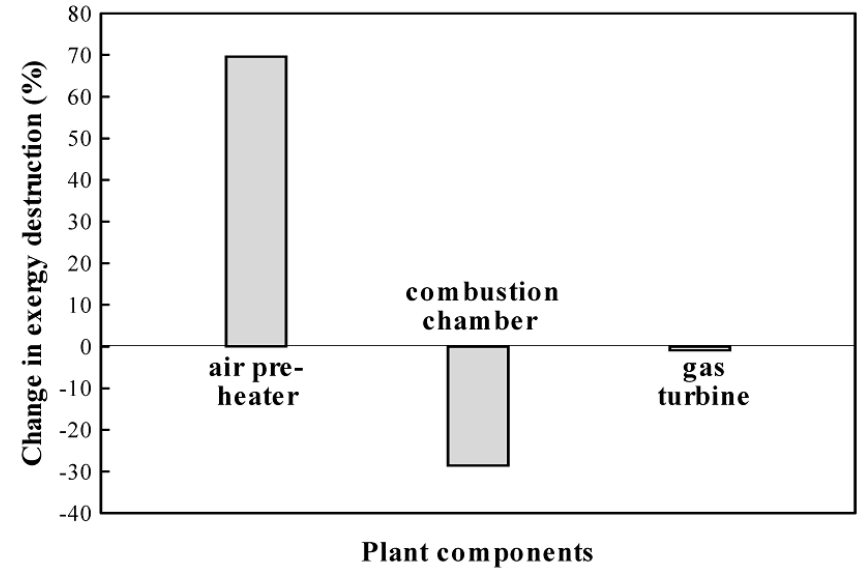


The effect on the plant exergetic efficiency and exergy destruction of a change in the $T I T$ is shown in Figures 6 and 7. To an increase in the TIT, there corresponds an increase in the exergetic efficiency of plant. As shown in Figure 7, the amount of exergy destruction in the plant decreases with an increase in TIT.

Figure 6 Effect on plant exergetic efficiency of a change in the turbine inlet temperature

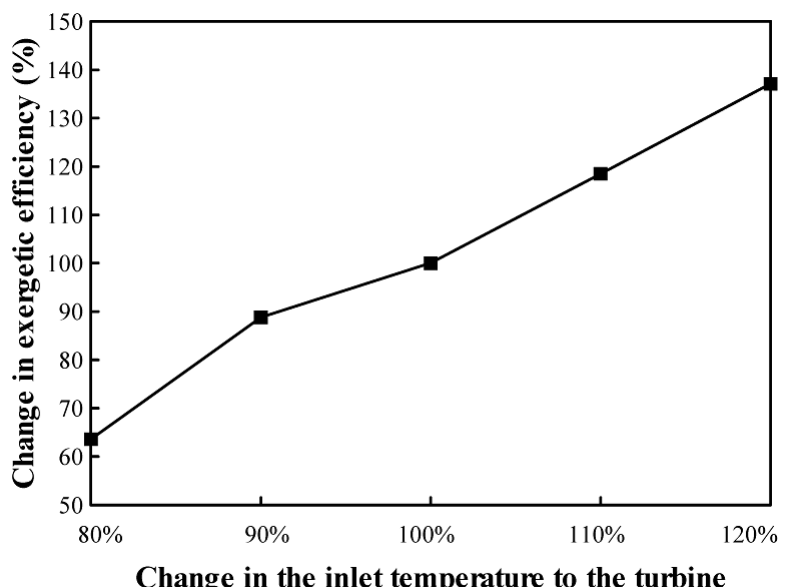

Figure 7 Effect on plant exergy destruction of a change in the turbine inlet temperature

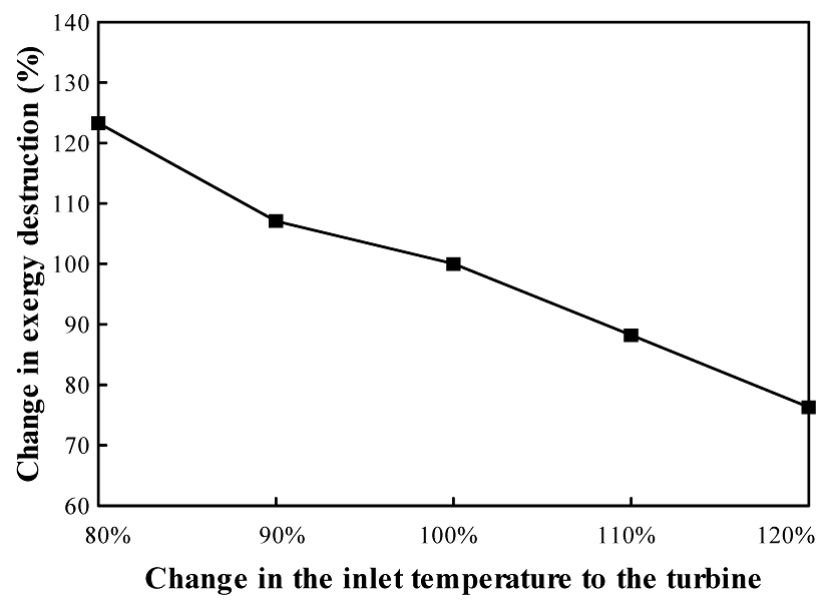

\section{Conclusions}

An exergy balance applied to a process or a whole plant tells us how much of the usable work potential, or exergy, supplied as the input to the system under consideration has been consumed (irretrievably lost) by the process. The loss of exergy, or irreversibility, provides a generally applicable quantitative measure of process inefficiency. 
The effect of the turbine inlet temperature on the exergetic efficiency and on the exergy destruction in 116-MW gas-turbine system has been analysed. It was confirmed that the exergetic efficiency and exergy destruction in the combustion chamber are mainly affected by this parameter. Considerable exergy destruction occurs in the combustion chamber only, and therefore, both the exergetic efficiency and the exergy destruction in the plant are affected mostly by the turbine inlet temperature.

\section{Acknowledgement}

The authors would like to thank Dr Korosh Sedighi and Eng. Alireza Imani of Iran for their precious collaboration.

\section{References}

Cengel, Y.A. and Boles, M.A. (1998) Thermodynamics - An Engineering Approach, Boston, MA: McGraw-Hill.

Flavio, G., Segio, A. and Silvia, A.N. (2000) 'Thermoeconomic evaluation of a gas turbine cogeneration system', Energy Conversion and Management, Vol. 41, pp.1191-1200.

Gordon, S. and Mcbride, B. (1971) 'Computer program for calculation of complex chemical equilibrium compositions, rocket performance, incident and reflected shocks, and Chapman-Jouguet detonations', NASA Report SP-273.

JANAF (1971) Joint Army-Naval-Air Force Thermochemical Tables, NSRDS-N3537, Washington DC, National Bureau of Standard Publications.

Jones, J.B. and Dugan, R.E. (1996) Engineering Thermodynamics, Upper Saddle River: Prentice-Hall.

Kotas, T.J. (1995) The Exergy Method in Thermal Plant Analysis, reprint edn, Malabar: Krieger.

Kwak, H., Kim, D. and Jeon, J. (2003) 'Exergetic and thermoeconomic analysis of power plants', Energy, Vol. 28, pp.343-360.

Kwon, Y., Kwak, H. and Oh, S. (2001) 'Exergoeconomic analysis of gas turbine cogeneration system', Exergy an Int. Journal, Vol. 1, pp.31-40.

Moran, M.J. and Shapiro, H.N. (2000) Fundamentals of Engineering Thermodynamics, 4th edn, New York, Wiley.

Oh, S., Pang, H., Kim, S. and Kwak, H. (1996) 'Exergy analysis for a gas-turbine cogeneration system', J Eng Gas Turb Power, Vol. 118, pp.782-791.

Verkhivker, G.P. and Kosoy, B.V. (2001) 'On the exergy analysis of power plants', Energy Conversion and Management, Vol. 42, pp.2053-2059.

Zhang, G., Hua, B. and Chen, Q. (2000) 'Exergoeconomic methodology for analysis and optimization of process systems', Computers and Chemical Engineering, Vol. 24, pp.613-618. 


\section{Nomenclature}

$\dot{E} \quad$ Rate of exergy flow $(\mathrm{kW})$

$c_{p} \quad$ Specific heat $(\mathrm{kJ} / \mathrm{kg} \mathrm{K})$

$\dot{m} \quad$ Mass flow rate $(\mathrm{kg} / \mathrm{s})$

$p \quad$ Pressure

$\dot{Q} \quad$ Heat transfer rate

$R \quad$ Universal constant $(\mathrm{kJ} / \mathrm{kg} \mathrm{K})$

$\dot{S} \quad$ Entropy flow rate $(\mathrm{kW} / \mathrm{K})$

$T \quad$ Temperature (K)

TIT Turbine inlet temperature (K)

$T_{0} \quad$ Ambient temperature

$\dot{W} \quad$ Power $(\mathrm{kW})$

Greek symbols

$\begin{array}{ll}\alpha & \text { Air-fuel ratio } \\ \beta & \text { Destruction of total inlet exergy into plant } \\ \eta_{b} & \text { Exergy efficiency }\end{array}$

\section{Subscripts}

$\begin{array}{ll}f & \text { Fuel } \\ i & \text { In } \\ o & \text { Out } \\ r e f & \text { Standard state } \\ A C & \text { Air compressor } \\ A P H & \text { Air preheater } \\ C C & \text { Combustion chamber } \\ C V & \text { Control volume } \\ D & \text { Destruction } \\ G T & \text { Gas turbine }\end{array}$

\section{Superscripts}

$\begin{array}{ll}m & \text { Material } \\ C H E & \text { Chemical } \\ P & \text { Mechanical } \\ T & \text { Thermal } \\ W & \text { Work or electricity }\end{array}$

